\title{
Correction to: Immunotherapy Alone or in Combination with Chemotherapy as First-Line Treatment of Non-Small Cell Lung Cancer
}

Puneet Saxena, $M D^{1}$

Pawan Kumar Singh, MD, $D M^{2}$

Prabhat Singh Malik, $M D, D M^{3}$

Navneet Singh, $M D, D M^{1, *}$

\author{
Address \\ *,1Department of Pulmonary Medicine, Postgraduate Institute of Medical Educa- \\ tion and Research (PGIMER), Sector 12, Chandigarh, 160012, India \\ Email: navneetchd@yahoo.com \\ ${ }^{2}$ Department of Pulmonary and Critical Care Medicine, Post Graduate Institute of \\ Medical Sciences (PGIMS), University of Health Sciences, Rohtak, Haryana, India \\ ${ }^{3}$ Department of Medical Oncology, Dr. B.R.A.I.R.C.H, All India Institute of Medical \\ Sciences, New Delhi, India
}

Published online: 12 September 2020

(C) Springer Science+Business Media, LLC, part of Springer Nature 2020

The online version of the original article can be found at https://doi.org/10.1007/s11864-020-00768-2

Correction to: Curr. Treat. Options in Oncol. (2020) 21: 69

https://doi.org/10.1007/s11864-020-00768-2

The original version of this article unfortunately contained mistakes. In Table 2, under the column 'Lead to death' in Row 5 [CheckMate-026], the figures should read as '0.7' for Experimental Arm and '1.1' for Comparator. Right now, these are printed as 0.007 and 0.011 respectively.

\section{Publisher's Note}

Springer Nature remains neutral with regard to jurisdictional claims in published maps and institutional affiliations. 